\title{
Figures and Maps
}

\section{Figures}

1 Miners propping workspace | 14

2 Delaware and Hudson Canal | 28

3 Scranton Iron Furnaces 49

4 Miners working on tracks in gangway | 56

$$
5 \text { Con-Acres | } 65
$$

6 Jason Torrey historical map of Wayne County $\quad 70$

7 Painting of lower barn (Jim Kilker) | 90

8 The author's father, Bill Conlogue | 99

9 ICS Railway School instructors at work | 119

10 Marvine culm banks burning | 146

11 Mine subsidence | 168

12 Natural gas drilling site in northeastern Pennsylvania $\quad 185$

Maps

1 Northeastern Pennsylvania | xvii

2 Scranton | xviii 
